\title{
Isolation and handedness of helical coiled cellulosic thickenings from plant petiole tracheary elements
}

\author{
Derek G. Gray
}

Received: 27 May 2014/ Accepted: 28 July 2014/Published online: 3 August 2014

(C) The Author(s) 2014. This article is published with open access at Springerlink.com

\begin{abstract}
Leaf stalks (petioles) are critical components of the vascular system that conducts water from the roots to the photosynthetic apparatus of most green plants. Helical coiled cellulosic microfibrils that reinforce the tracheary elements in plant leaf petioles were isolated by a gentle treatment with alkali and acid chlorite from celery and from a number of tree species, including sugar maple, London plane, horse chestnut, tulip tree, paulownia and ginko. Analysis of the hydrolysate of celery coils gave glucose as the main product, but significant quantities of xylose and other sugars were also detected. Polarized light microscopy was used to determine the location, dimensions and handedness of the coils. The coils were made up of single or multiple parallel strands in contact, ranging up to $35 \mu \mathrm{m}$ in diameter and several $\mathrm{cm}$ in length. The strand structure was chiral; significantly, only lefthanded helices were observed. An attempt is made to rationalize the left-handed structure by comparison with the spontaneous handedness observed in vitro for cellulose nanocrystals suspensions. The ubiquitous presence of coiled thickenings in petiole vascular elements indicates their importance in plant functions.
\end{abstract}

D. G. Gray $(\bowtie)$

Department of Chemistry, McGill University, 3420 University Street, Montreal, QC H3A 2A7, Canada e-mail: derek.gray@mcgill.ca
Keywords Plant petioles - Helical thickenings · Left-handed coils · Polarized light microscopy · Vascular elements $\cdot$ Chiral structures

\section{Introduction}

Preliminary reports described the isolation of long tightly-coiled cellulosic filaments from the tracheary elements of celery (apium graveolens L.) (Ulkem and Gray 2006) and some tree species (Gray and Lucate 2009). Spiral thickening of the xylem secondary wall is of course well-known, but we were interested to note that the helical coils all appeared to be left-handed. This behaviour contrasts with that of the coils produced by in vitro electro-spinning of cellulose derivatives, where both left- and right-handed coils were observed (Godinho et al. 2009). Manifestations of the molecular chirality of cellulosic materials have been reported at the levels of individual cellulosederived polymers (Werbowyj and Gray 1976; Harkness and Gray 1994), cellulose nanocrystal suspensions (Revol et al. 1992), thin wood sections (Gray and Kam 1997) and paper (Gray 1989). The chiral twisting of wood and paper was attributed to the right-handed twist of the cellulose microfibrils observed in the S2 layer of virtually all wood cells (Meylan and Butterfield 1978a, b).

The helical orientation of the cellulose microfibrils is thought to be controlled during deposition by the 
orientation of cortical microtubules (Abe et al. 1995), and the helical winding and fibril angle are important in determining the mechanical properties of wood (Barnett and Bonham 2004) and wood pulp fibres (Page and El-Hosseiny 1983). The helical secondary wall thickenings often observed in water-conducting cells or tracheary elements in the primary xylem of non-woody plants allow for cell extension during elongation and growth of the surrounding tissue during plant development, and may strengthen the cell walls against collapse due to the negative pressure in the plant vascular system. In general, the orientation of cellulose microfibrils in the cell wall governs many plant functions (Burgert and Fratzl 2009). Again, there is much evidence that the major factor in controlling microfibril orientation during cell growth is the orientation of the cortical microtubules, but some other factor must also be involved (Baskin 2001).

Whatever the mechanism or mechanisms that result in the orientation of cellulose microfibrils, it is evident that the arrangement of microfibrils in plant cell walls is often chiral. A chiral physical interaction between microfibrillar elements of cellulose has also been demonstrated in vitro (Revol et al. 1992), and this raises the general question whether and under what circumstances this chiral interaction might also influence the processes that are involved in cellulose deposition. In this paper, we describe the isolation of cellulosic coils from tracheary elements of leaf petioles, the methods we used to determine coil handedness, and we comment on the possible significance of the observations.

\section{Experimental}

\section{Materials}

Fresh celery (Apium graveolens L.) was obtained from a local market. Strands of vascular bundles (the "strings" in celery), approximately $25 \mathrm{~cm}$ long, were stripped from mature petioles (Fig. 1). After boiling in water for $30 \mathrm{~min}$, the strands were soaked in $5 \% \mathrm{w} / \mathrm{v}$ $\mathrm{NaOH}$ solution for $1 \mathrm{~h}$ at room temperature. After washing thoroughly, the strings were bleached with $500 \mathrm{~mL}$ of solution containing $40 \mathrm{~g} \mathrm{NaClO}_{2}$ and $7.5 \mathrm{~g}$ $\mathrm{CH}_{3} \mathrm{COOH}$ at $35^{\circ} \mathrm{C}$ for $1 \mathrm{~h}$. The now-white strings were washed several times with distilled water until the $\mathrm{pH}$ of the water remained unchanged, and were

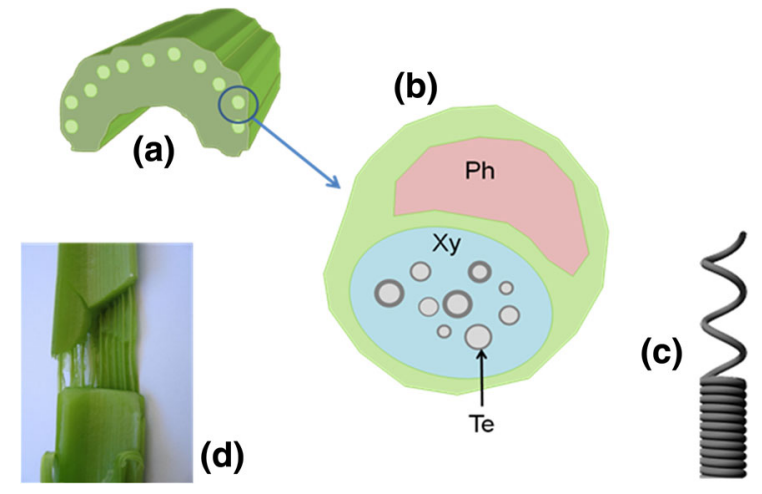

Fig. 1 a Sketch of celery petiole cross-section. b Sketch of vascular bundle cross-section. $P h$ phloem, $X y$ xylem, Te tracheary elements. c Sketch of coiled secondary wall thickening of tracheary element. d Celery petiole showing orientation of vascular bundles. The coils are aligned with their long axis parallel to the long axis of the petiole

stored moist under refrigeration. The carbohydrate content of the celery vascular bundle components was analysed by acid hydrolysis and high-performance anion-exchange chromatography with pulsed amperometric detection (Sullivan and Douek 1994).

Leaves were collected in summer from trees on the campus of McGill University, Montreal, or in the vicinity thereof. The leaf petioles were cut into $\sim 1 \mathrm{~cm}$ lengths, and as much as possible of the petiole epidermis was removed with a razor blade, and discarded. The remains were sliced lengthwise. Cellulose was isolated from the petiole slices by a sequence of chemical treatments, with rinsing in water between each step. First, the samples were boiled for $1 \mathrm{~h}$ in distilled water, then in aqueous sodium dodecyl sulfate (1.5-2 \%) for $1 \mathrm{~h}$. This was followed by a basic treatment in $5 \% \mathrm{NaOH}$ for $1 \mathrm{~h}$ at room temperature, or in $3.5 \%$ aq. $\mathrm{NaOH}$ at $85-100{ }^{\circ} \mathrm{C}$ for $45-55 \mathrm{~min}$, depending on the sample. Finally, after thorough rinsing in water until neutrality, the fibrous mass was bleached in a $8-10 \%$ soln. of sodium chlorite $\left(\mathrm{NaClO}_{2}\right)$ in $0.4 \mathrm{M}$ acetic acid for $3 \mathrm{~h}$ at ambient temperature. For some samples, it was necessary to repeat the bleaching step. After rinsing, the petiole structure was then partially disrupted by a brief ultrasonic treatment in water.

\section{Polarized light microscopy}

The initial detection of the isolated coiled tracheary elements stemmed from observations of the treated 

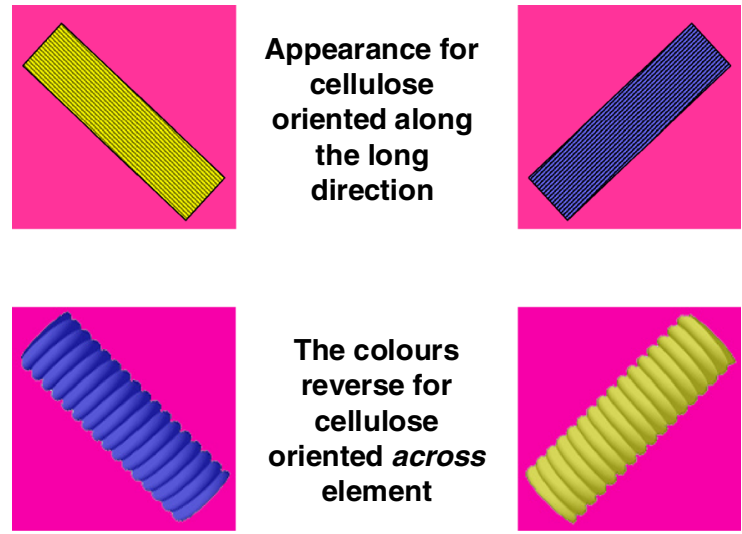

Fig. 2 Colours observed when viewing vascular elements with optical microscope between crossed polars with $530 \mathrm{~nm}$ red retardation plate

petiole tissue dispersed in water between microscope slide and cover glass. The wet vascular bundles from the petioles were spread on microscope slides and examined by polarized-light microscopy (Nikon Microphot-FXA with Nikon Coolpix 990 digital camera, or Nikon Eclipse LV100, with DS-Fi1 camera). The cellulose coils were readily distinguished from other vascular components by the transverse orientation of the cellulose major refractive index, as indicated by viewing between crossed polarizers with a $530 \mathrm{~nm}$ retardation plate. With this retardation plate in place, isotropic regions of the microscope image appear red, and birefringent elements appear blue or yellow when oriented at as shown in Fig. 2. By simply rotating the sample stage, the colour change gives the orientation of the cellulose in the sample.

To deduce the handedness of the coils requires some care. Viewed from above, a left-handed coil lying horizontally on a microscope slide appears to be a tight S-helix. This is the usual situation. However some light may be transmitted through the cellulose coils, and if the microscope is focused on the bottom of the coils rather than the top, a tight Z-helix is observed (Fig. 3). The apparent change from S- to Z-helix is observed as the plane of focus is moved from top to bottom of the sample. Often the handedness is more readily determined on stretched parts of the coils.

\section{Atomic force microscopy (AFM)}

Segments of wet vascular bundles, approximately $5 \mathrm{~mm}$ long, were placed onto a standard microscopy

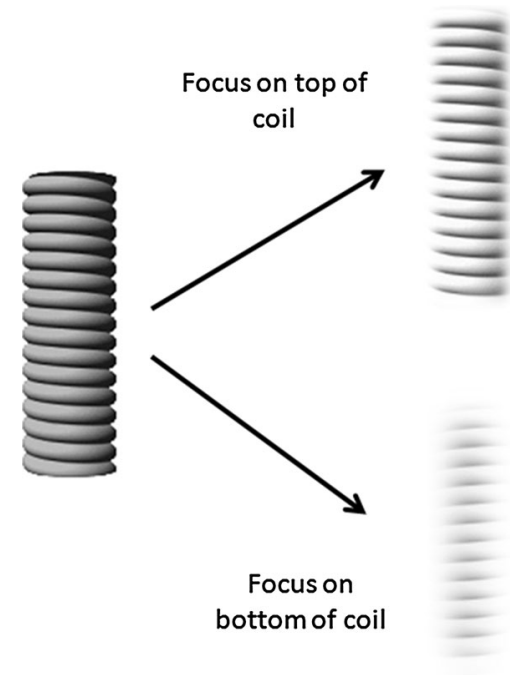

Fig. 3 Sketch showing that focusing on the top of a left-handed coil gives an apparent S-helix, while focusing on the bottom of the coil gives an apparent Z-helix

slide and the long helical coils were separated from other tissues with fine tweezers while viewed with a polarized-light microscope. A single helix was placed onto a piece of freshly cleaved mica and the mica was mounted on an AFM disk with double sided adhesive tape. AFM images were recorded with a Digital Instruments Multimode scanning probe microscope with a Nanoscope IIIa controller. The atomic force microscope was operated in tapping mode in air using silicon cantilevers with a resonance frequency of 250-300 kHz.

\section{Results}

We consider first the results for celery. After the chemical treatment, the vascular bundles stripped from celery appeared as long flexible white strings (Fig. 4). When the string was gently teased apart in water and viewed with a polarized light microscope and red retardation plate, the sample displayed colors (Fig. 2) that depended on the orientation of the birefringent fibrillar material. On the left of Fig. 5a, the fibrils displayed the blue and yellow colors characteristic of cellulose oriented along their length. However, a significant portion of the sample showed colors corresponding to cellulose oriented across the string direction (on the right side of Fig. 5a). The transverse orientation of cellulose was confirmed by 


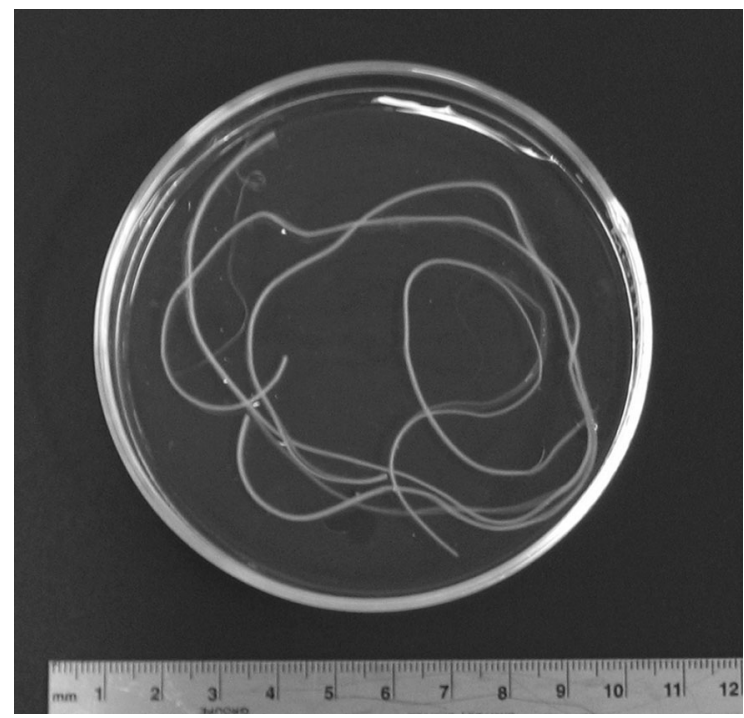

Fig. 4 Vascular bundle isolated from celery, after chemical treatment

selecting a single coil (Fig. 5b), and observing the change from blue to yellow as the sample stage was rotated through $90^{\circ}$ (Fig. 5c).

The transverse orientation of cellulose was due to the helical orientation of the cellulose strands isolated from these tracheary elements. At higher magnification, the helical coils were seen to be continuous, with strands in contact, but the coils could easily be pulled apart to give very long continuous strands of cellulose (Fig. 6). The isolated coils in water are typically $\sim 50 \mu \mathrm{m}$ in diameter, and the diameter of the cellulose fibril strand that forms the coil is $\sim 5 \mu \mathrm{m}$; the pitch of the contact helix is thus also $\sim 5 \mu \mathrm{m}$. Using the microscope method described above, it was observed that the helical coils were invariably left-handed, and if undisturbed, the individual turns of the coils were in contact with each other. Helical "contacting coils" have long been recognised in the celery stem, along with more extended coils and ring-shaped thickenings (Fahn 1990), but as far as we know, their isolation and handedness have not been reported previously.

The surface morphology of an individual strand was observed by AFM. Tapping mode height images (Hanley et al. 1992) of the surface of the dry strand show a pattern of poorly defined corrugations or ridges at an angle of very approximately $60^{\circ}$ to the fibril direction (Fig. 7b), corresponding to a shallow righthanded helix. The AFM images of the surface also
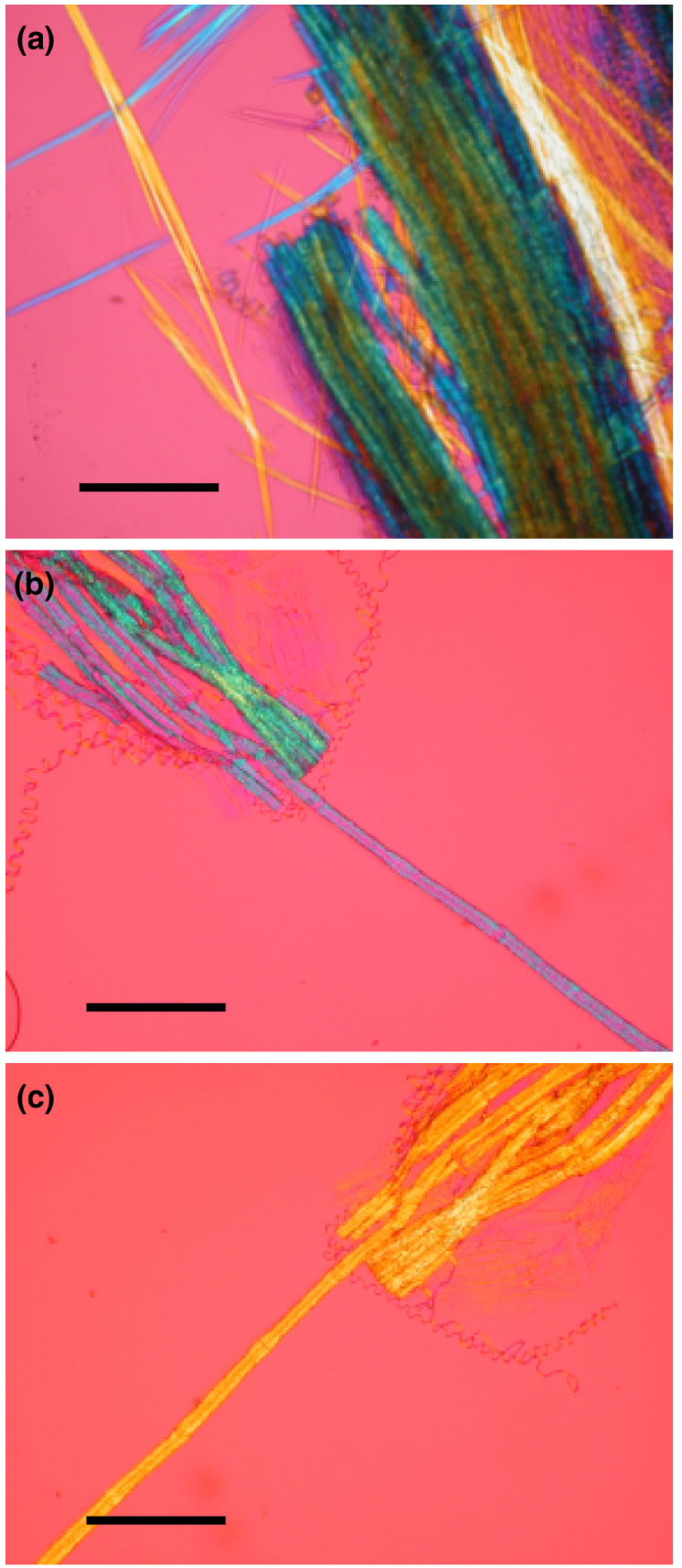

Fig. 5 Low-magnification images of vascular elements of celery, between crossed polars with $530 \mathrm{~nm}$ red retardation plate. Scale bar $0.5 \mathrm{~mm}$. a Regular cellulose fibrils on left, cellulose coil bundles, centre and right. b A single coil drawn from bundle and oriented at $45^{\circ}$ to polarizer and analyser. $\mathbf{c}$ The same coil, rotated by $90^{\circ}$

show what appear to be randomly oriented "nanofibrils", with cross-sectional dimensions of the order of $10 \mathrm{~nm}$ (Fig. 7a, b). Precise AFM measurements of 


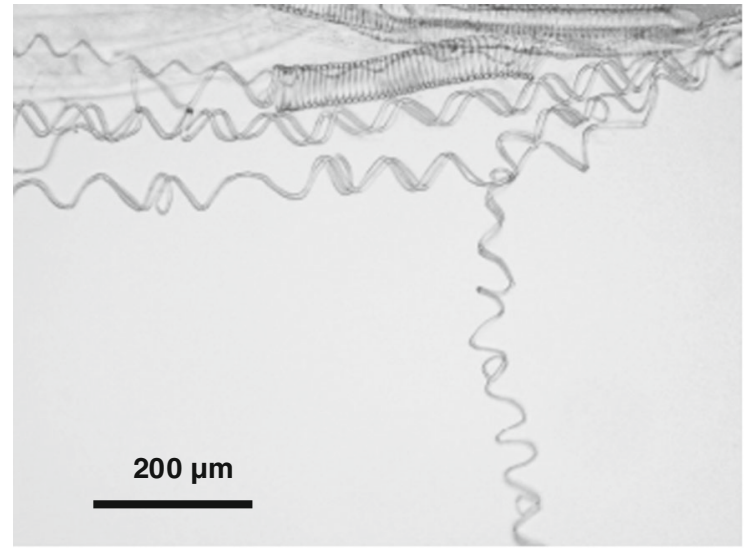

Fig. 6 Contacting and stretched helical coils from celery, showing the continuous nature of the cellulose strands

nanofibril dimensions in cell walls are difficult because of sample-tip artefacts (Hanley et al. 1992), but it was possible to dry down individual nanofibrils from celery and image them on a mica surface. Measurement of the height of the isolated nanofibrils gave more reliable values, of the order of $3 \mathrm{~nm}$. This is the same as the crystallite size of celery cellulose, measured perpendicular to the (020) plane by X-ray diffraction (Revol et al. 1987). It must be stressed that whatever the orientation of the cellulose nanofibrils at the surface, the cellulose is oriented predominantly along the strand, as indicated by the birefringence observed by polarized light microscopy. It is also possible that the larger scale corrugations are artefacts of the drying process.

While celery is a very convenient petiole for study because of its unusually large dimensions and ready availability, we wanted to check if cellulose coils from more typical leaf petioles could be isolated and characterized. The leaf petioles from a number of angiosperm and one gymnosperm tree species (Table 1) were isolated and examined. The coiled elements are readily identified by their colour in the polarising microscope. Figure 8 a shows a sample of a Pawlonia petiole that was simply treated by boiling water, rather than by the chemical treatment. The coils are nevertheless readily seen at low magnification as the blue elements. At higher magnification, the S-helix observed when focussed on the top of the coils (Fig. 8b) indicates a left-handed helical coil. This changed to an apparent $\mathrm{Z}$ helix as the focus was lowered to the bottom of the coils (Fig. 8c), but this
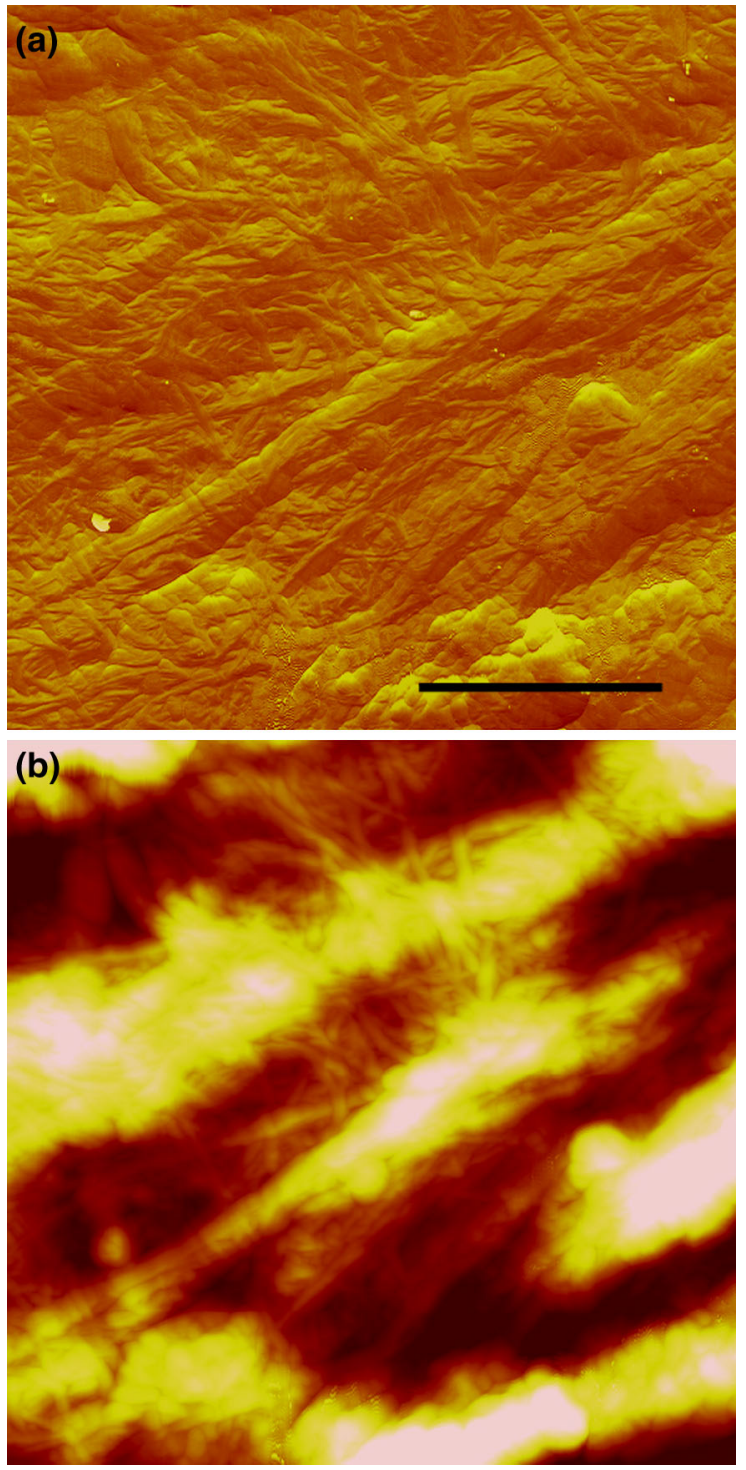

Fig. 7 Tapping mode AFM images of a typical area on the surface of a helical strand isolated from a celery petiole. The long axis of the strand is vertical. a Phase image; $\mathbf{b}$ height image of same area, $\mathrm{z}$ range, $100 \mathrm{~nm}$. Scale bar $1 \mu \mathrm{m}$

was an artefact: the helix remained left-handed, as described in the experimental section. Left-handed coils were observed for all the species examined.

Stretching out the coils indicates that these leaf petioles often contain multiple-stranded helices (Fig. 9). A coil isolated from a tulip tree petiole is shown in Fig. 10 (In this case again, the petiole was simply treated repeatedly with boiling water, and the tracheary elements were then mechanically separated). The undeformed coil is seen on the right. The 
Table 1 Tree species displaying a left-handed helical arrangement of the coils in petiole tracheary elements

\begin{tabular}{ll}
\hline Norway maple & Acer platanoides \\
Sugar maple & Acer saccharum \\
Horse chestnut & Aesculus hippocastanum \\
Ohio Buckeye & Aesculus glabra \\
Choke-cherry & Amelanchier sp. \\
Ginko & Ginko biloba \\
Honey locust & Gleditsia triacanthos \\
Tulip tree & Liriodendron tulipifera \\
Magnolia & Magnolia virginiana \\
Paulownia & Paulownia tomentosa \\
London Plane & Platanus $\times$ hispanica \\
White Oak & Quercus alba \\
Willow & Salix sp. \\
Viburnum & Viburnum sp. \\
\hline
\end{tabular}

No right-handed coils were observed in these or other species

stretched region to the left shows multiple coils of three or four individual fibrils. Breaks in the fibrils result in some single and double coils in the image. Similar multiple coils were usually observed in samples isolated from the maple and chestnut petioles, but were very rare in the celery petioles observed previously. Single and multiple (achiral) rings were also observed.

In general, the isolated coils were much longer than the field of view in the microscope, and the ends of the coils looked as if they had been ruptured during isolation and subsequent treatment. However, we did observe tapered ends of coils, where the diameter of the coil (but not the diameter of the individual strand) decreased towards the end (Fig. 11). The diameters of the contacting coils were typically between 15 and $35 \mu \mathrm{m}$, with lengths up to several $\mathrm{cm}$, but the range of sizes varied widely within and between species to species. The fibrillar strands that made up the coils were circular in cross-section and about $0.5 \mu \mathrm{m}$ in diameter.

In addition to the petioles of tree species listed in Table 1, we also isolated left-handed coils from plants as diverse as rhubarb (Rheum rabarbarum), squash (Cucurbita sp) and banana (Musa sp.) Similar helical coiled structures have been isolated from wheat straw (Liu et al. 2005). Examination of the fossil records of primitive vascular plants also shows evidence of coiled structures, some of which clearly appear to be left-handed [see for example the image of a vascular
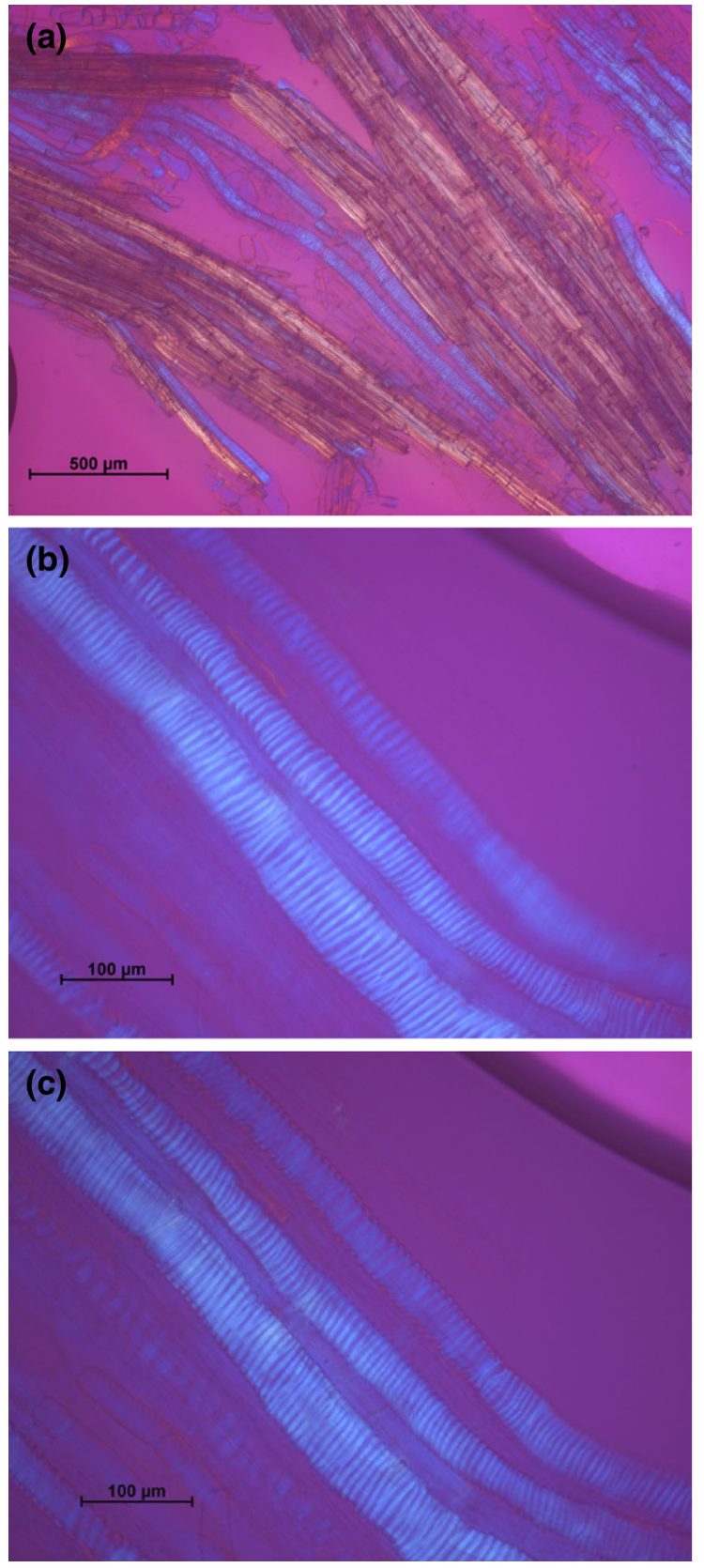

Fig. 8 Coiled tracheary elements from Paulownia tomentosa petiole. Crossed polars with $530 \mathrm{~nm}$ red retardation plate. a Low magnification allows selection of coils by their blue colour; $\mathbf{b}$ focus on upper surface of coils; $\mathbf{c}$ focus on lower surface of the same coils shown in $\mathbf{b}$

strand of Cooksonia pertoni in the paper by Edwards et al. (1992)]. Recently, the left-handed coils isolated from lotus plants (Nelumbo nucifera) have been used as templates to prepare silver-coated conducting microcoils (Kamata et al. 2011). 


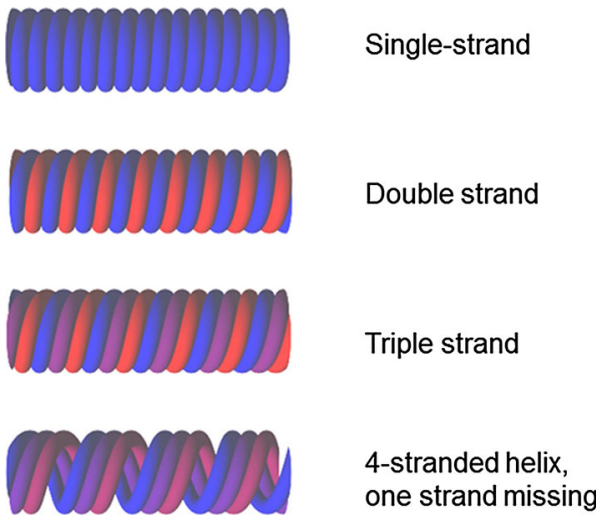

Fig. 9 Sketch showing typical multiple-stranded left-handed helices, as observed in isolated tracheary coils

\section{Discussion}

Helical thickenings in tracheary elements are wellknown, but their isolation as individual coils has seldom been reported. Preliminary analysis for constituent sugars showed a predominance of glucose, as would be expected for cellulose-containing materials (Table 2). Both isolated coils and fibrillar material were analysed separately, and gave different results. The coils were richer in xylose, and showed a lower recovery of sugars than the fibrillar material, implying that the coils contain more non-cellulose material that was removed during hydrolysis. The analysis results, normalized to $100 \%$ recovery, confirm that significant quantities of polysaccharide components other than cellulose are present, despite the fairly stringent purification procedures employed to treat the celery vascular bundles.

Contacting coils were observed for all the species examined, and all were left-handed helices. The isolation of the coils provides information not readily apparent from conventional sectioning and microscopy. Several properties of the isolated coils are

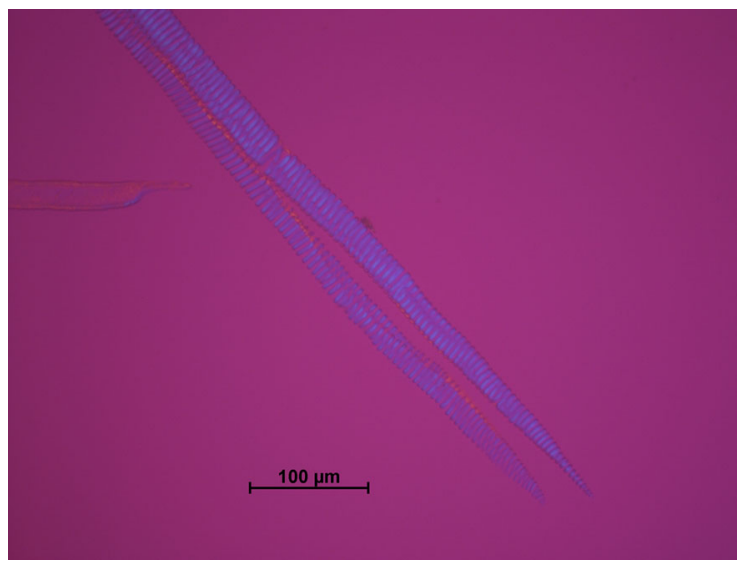

Fig. 11 Tapered ends of coils observed for Magnolia virginiana. Crossed polars with $530 \mathrm{~nm}$ red retardation plate

surprising. First, the coils, which may be single, double or multiple stranded, are very long (many centimeters in the case of coils isolated from celery and rhubarb petioles). This means that, even when tightly coiled, the coils would appear to be much longer than the individual protoxylem cells. However, the coils show a periodicity along their length, which may correspond to the original cell length (Fig. 12). Stretching the coil (Fig. 6) shows that the individual strands are continuous, but when stretched, the individual strands show kinks at the positions marked with arrows in Fig. 11, as if the coils were imperfectly welded together at these positions.

As has long been recognized, the main role of the spiral thickening is to reinforce the walls of the tracheary elements, which have to withstand the negative pressure within the plant vascular system during transpiration (Zimmermann 1983). The coils thus resemble the spiral reinforcements in some garden hoses, with the major difference that the tracheary elements are under negative rather than

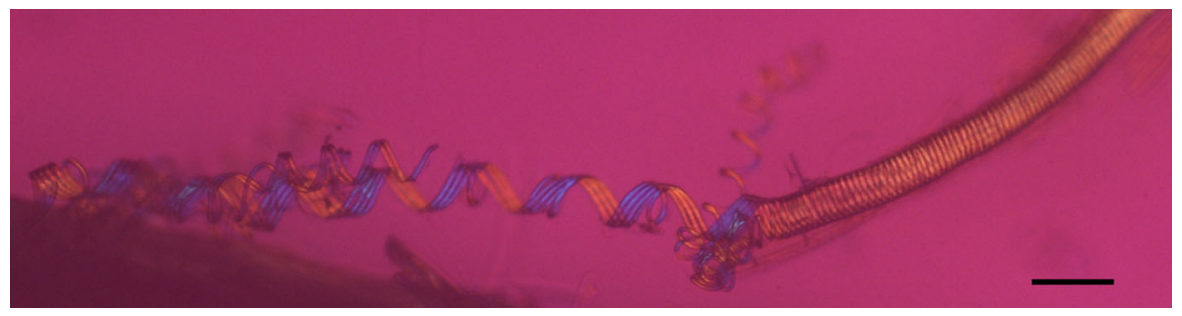

Fig. 10 Stretched multistrand coil from Liriodendron tulipifera petiole. Crossed polars with $530 \mathrm{~nm}$ red retardation plate. Scale bar $100 \mu \mathrm{m}$ 
Table 2 Sugar analysis of contacting coils and fibrillar material isolated from celery vascular bundles

\begin{tabular}{lllccc}
\hline Sample & $\begin{array}{l}\text { Sample } \\
\text { weight (mg) }\end{array}$ & $\begin{array}{l}\text { Glucose } \\
(\%)\end{array}$ & $\begin{array}{l}\text { Xylose } \\
(\%)\end{array}$ & $\begin{array}{l}\text { Arabinose, galactose, } \\
\text { mannose, sum (\%) }\end{array}$ & \% Recovery \\
\hline Tracheary coils & 52.4 & 37.4 & 7.9 & 4.2 & 49.5 \\
Normalized (\%) & & 74.9 & 16.7 & 8.5 & 100 \\
Fibrillar material & \multirow{2}{*}{16.1} & 48.5 & 4.2 & 9.7 & 62.3 \\
Normalized (\%) & & 77.5 & 7.0 & 15.5 & 100 \\
\hline
\end{tabular}

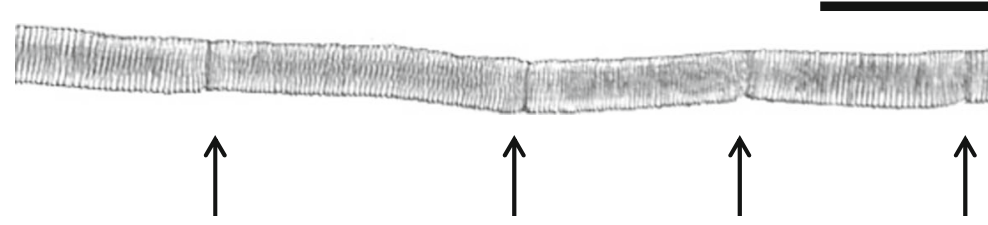

Fig. 12 Periodicities along a portion of a coil isolated from a celery petiole. Gray scale image from polarized light microscopy. The arrows indicate apparent "joints" in the coil. Scale bar $500 \mu \mathrm{m}$

positive pressure. The vascular system of trees in particular contains many safeguards against interruption of sap flow, and in tree leaf petioles, where the negative pressure is high and unprotected by the solid wood structure, the contacting-coil structure seems to be an elegant way to reinforce a conduit, while retaining some flexibility.

The contacting coils might play another role in strengthening petiole structure. The mechanical properties of petioles of annual plants and deciduous trees depend mainly on the internal turgor pressure; the fibrillar cellulosic components (and the petiole epidermis) show high strength and modulus only in tension. However it seems possible that the contacting coils, held in restraint by the surrounding fibrillar material, can contribute a high compressive modulus, and hence supplement the turgor pressure in stiffening the structure to bending (Fig. 13). The outer epidermis of the petiole (a) is strong in tension, both radially and axially, and resists the internal turgor pressure. The epidermis is reinforced by fibrillar material (often collenchyma cells) (b), strong in tension and oriented axially along the petiole. The vascular bundles contain fibrillar material, but also the coiled tracheary elements (c) which should be strong in compression. Of course, the cross-sectional shape (Pasini 2008) and distribution of the components in the petiole will all contribute to the effective stiffness and strength of the petiole in supporting the leaf in its role of light interceptor (Niklas 1992). While the contribution of the coiled tracheary elements to the mechanical performance of the petiole is speculative, there seems little doubt that the coiled structure contributes to the ability of the petiole vascular system to maintain a negative pressure as the leaf is buffeted by the wind.

Only left-handed helical coils were observed in this work. This complements the observation that the cellulose microfibrils in the S2 layer of the secondary wall of virtually all wood fibres follow a shallow righthanded helix (Meylan and Butterfield 1978a), whereas the same authors found that helical thickenings observed in some hardwood vessels and softwood tracheids were in the form of S-helices, i.e., of the opposite handedness (Meylan and Butterfield 1978b). The relationship between these macroscopic manifestations of chirality and the intrinsic chirality of glucose and cellulose at the molecular level has proved elusive. At a length scale between the molecular and the macroscopic, there is experimental (Hanley et al. 1997; Hirai et al. 1998) and theoretical (Matthews et al. 2006) evidence that individual crystalline cellulose nanofibrils also form right-handed twisted structures. The details of how these chiral structures pack together to produce the chiral structures observed at larger length-scales remain speculative, but the experimental observation that suspensions of cellulose nanocrystals only form left-handed helicoidal arrangements (Fig. 14) implies a chiral interaction between linear segments of crystalline cellulose, such that parallel alignment is not the preferred state.

This experimental observation may be used to rationalize the difference in handedness between the 


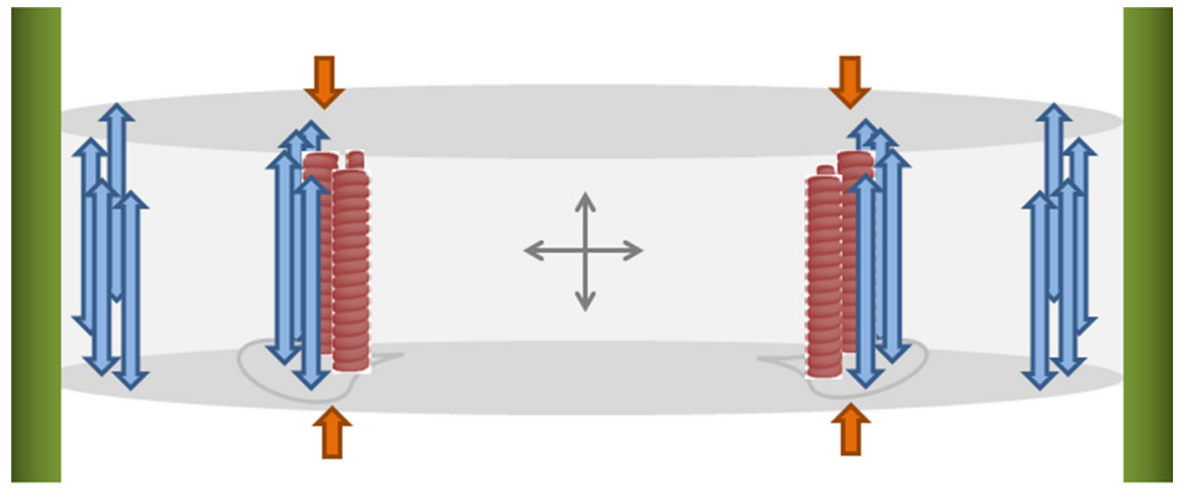

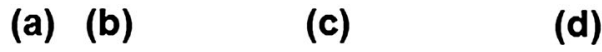

Fig. 13 Sketch of petiole mechanics. The petiole is oriented vertically. a Outer epidermis, providing tensile strength both axially and radially. b Cellulosic fibrillar material. c Vascular bundle, containing fibrillar material, and tracheary elements. A

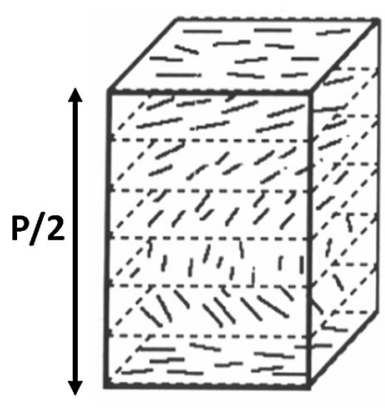

(a)

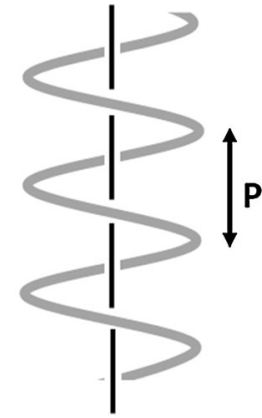

(b)
Fig. 14 Sketch of left-handed helicoidal (a) and helical (b) structures, where the arrows indicate the pitch, $\mathrm{P}$, and axis direction

right-handed organization of microfibrils in the wood cell secondary wall and the left handed helical structure of the tracheary elements observed in this work. To form the preferred right-handed helical orientation in the S2 layer, the orientation of the cellulose microfibrils must depart from a parallel (achiral) orientation (Fig. 15a in the manner shown schematically in Fig. 15b). The microfibril wraps around the long axis of the wood fiber in a righthanded helix, such that, when viewed from any position along the fibre, the microfibril orientation is offset from the axis as shown in Fig. 15c.

To form the preferred left-handed helical structure of the tracheary elements, the orientation of the cellulose in the coils must also depart from the achiral organization, in this case shown by individual ring- turgor pressure (d) is present outside the tracheary elements. The blue arrows indicate elements with high tensile modulus, the red arrows indicate elements that may contribute a high compressive modulus

like thickenings (Fig. 15d) often observed in the vascular systems, to give a left-handed helical coil (Fig. 15e), whose orientation is offset from the achiral case as shown in Fig. 15f. In both cases, the direction of the offset corresponds to a left-handed helicoidal arrangement of cellulosic material when viewed perpendicular to the axis of the coil. This is the same left-handed orientation as is observed experimentally for the organization of chiral nematic cellulose nanocrystals suspensions and films along the helicoidal axis (Revol et al. 1992). In other words, the observed alignments of cellulose microfibrils in shallow right-handed helices (in the S2 layer of tracheids) and in tight left-handed helices (in the tracheary thickenings in petioles and vessels) are both in accord with the in vitro observations of a left-handed helicoidal arrangement of cellulose nanocrystals in CNC suspensions. Whether and how this physical interaction can influence the complex biochemical and topological processes controlling microfibril orientation during cell growth is unclear.

Of course, the primary purpose of the tracheary elements is the transport of water. As the coiled structures seem ubiquitous; they may have some role in the capillary forces that deliver water to the photosynthetic apparatus in the leaves. Kohonen and Helland (2009) showed that the helical thickenings in xylem vessels enhanced their wettability, and proposed that this may facilitate the refilling of embolized tracheary elements. Their presence in leaf petioles may indicate a similar function, in addition to the reinforcement they provide. 
Fig. 15 Schematic representation of the microfibril orientation in shallow (b) and tight (e) helices relative to the achiral orientations (a) and (d). The displacement of orientation (c),

(f) corresponds to the small angular displacement observed in chiral nematic suspensions (Fig. 14)

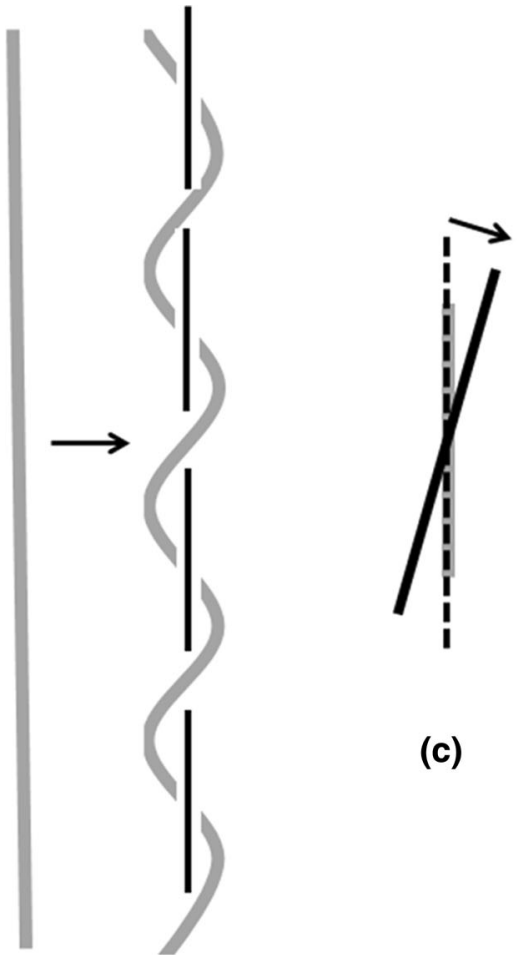

(a) (b) (d)

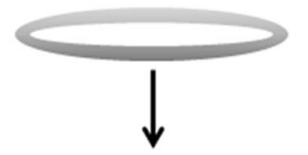

(e)
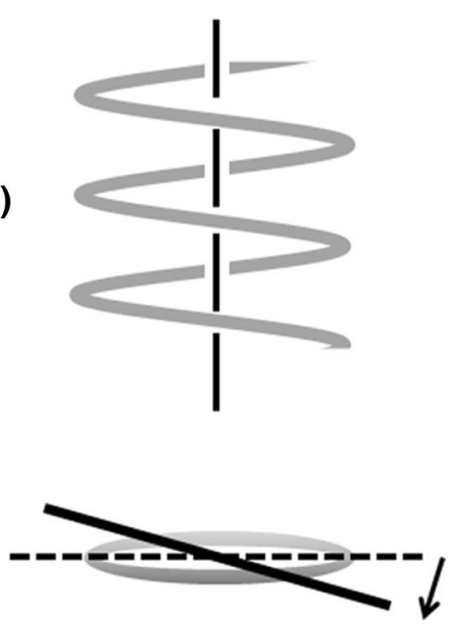

(f)

\section{Conclusions}

Helical coils could be isolated in all of the species examined. The diameters of the coils usually range between 15 and $35 \mu \mathrm{m}$, but the sizes and range of diameters vary from species to species; we observed coils up to several $\mathrm{cm}$ long. The fibrillar strand that makes up the coil is circular in cross-section, around $0.5 \mu \mathrm{m}$ in diameter. Initially the strands in a coil are in contact, but the coils can easily be extended, showing that they can be single- or multiple-stranded helices. (Individual single rings were also observed.) To date, all the coils observed have been left-handed helices. As to function, it seems clear that the coils form a reinforcement to help prevent the collapse of the vascular elements under the negative pressure present in plant vascular systems. More speculatively, the transverse strands in the coils, when in contact, can help stiffen the petiole by providing some compressive strength to supplement the tensile strength of the axially oriented fibrillar elements.

Acknowledgments I thank the Natural Sciences and Engineering Research Council of Canada for a Discovery Grant. Dr. N. Ulkem and J. Lucate assisted with the petiole

sample collection and isolation, and Lisette Nadeau at FPInnovations performed the carbohydrate analysis. I'm also indebted to a number of plant scientists and reviewers for patient and helpful comments.

Open Access This article is distributed under the terms of the Creative Commons Attribution License which permits any use, distribution, and reproduction in any medium, provided the original author(s) and the source are credited.

\section{References}

Abe H, Funada R, Imaizumi H, Ohtani J, Fukazawa K (1995) Dynamic changes in the arrangement of cortical microtubules in conifer tracheids during differentiation. Planta 197(2):418-421

Barnett JR, Bonham VA (2004) Cellulose microfibril angle in the cell wall of wood fibres. Biol Rev 9(2):461-472

Baskin TI (2001) On the alignment of cellulose microfibrils by cortical microtubules: a review and a model. Protoplasma 215:150-171

Burgert I, Fratzl P (2009) Plants control the properties and actuation of their organs through the orientation of cellulose fibrils in their cell walls. Integr Comp Biol 49:69-79

Edwards D, Davies KL, Axe L (1992) A vascular conducting strand in the early land plant Cooksonia. Nature 357:683-685

Fahn A (1990) Plant Anatomy, 4th edn. Pergamon, New York

Godinho MH, Canejo JP, Pinto LFV, Borgesa JP, Teixeira PIC (2009) How to mimic the shapes of plant tendrils on the nano 
and microscale: spirals and helices of electrospun liquid crystalline cellulose derivatives. Soft Matter 5:2772-2776

Gray DG (1989) Chirality and curl of paper sheets. J Pulp Pap Sci 15(3):J105-J109

Gray DG, Kam A (1997) Chiral characteristics of thin wood sections. Holzforschung 51:1-5

Gray DG, Lucate JG (2009) Chiral structure in petiole vascular bundles. In: Thibaut B (eds) Proceedings of the sixth plant biomechanics conference, Cayenne, French Guyana, 16-21 Nov 2009, pp 439-443

Hanley SJ, Giasson J, Revol J-F, Gray DG (1992) Atomic force microscopy of cellulose microfibrils: comparison with transmission electron microscopy. Polymer 33(21):4639-4642

Hanley SJ, Godbout L, Revol J-F, Gray DG (1997) Atomic force microscopy and transmission electron microscopy of cellulose microfibrils from Micrasterias denticulata; evidence for a chiral helical microfibril twist. Cellulose 4(3):209220

Harkness BR, Gray DG (1994) Chiral nematic mesophases of lyotropic and thermotropic cellulose derivatives. In: Shibaev V, Lam L (eds) Liquid crystalline and mesomorphic polymers. Springer, New York, pp 298-323

Hirai A, Tsuji M, Horii F (1998) Helical sense of ribbon assemblies and splayed microfibrils of bacterial cellulose. Sen-I Gakkaishi 54(10):506-510

Kamata K, Suzuki S, Ohtsuka M, Nakagawa M, Iyoda T, Yamada A (2011) Fabrication of left-handed metal microcoil from spiral vessel of vascular plant. Adv Mater 23(46):5509-5513

Kohonen MM, Helland $\AA$ (2009) On the function of wall sculpturing in xylem conduits. J Bionic Eng 6(4):324-329

Liu R, Yu H, Huang Y (2005) Structure and morphology of cellulose in wheat straw. Cellulose 12(1):25-34

Matthews JF, Skopec CE, Mason PE, Zuccato P, Torget RW, Sugiyama J, Himmel ME, Brady JW (2006) Computational evidence for chiral cellulose $\mathrm{I} \beta$ microfibrils. Carbohydr Res 341:138-152

Meylan BA, Butterfield BG (1978a) Helical orientation of the microfibrils in tracheids, fibres and vessels. Wood Sci Technol 12:219-222

Meylan BA, Butterfield BG (1978b) Occurrence of helical thickenings in the vessels of New Zealand woods. New Phytol 81(1):139-146

Niklas KJ (1992) Petiole mechanics, light interception by lamina, and "economy in design". Oecologia 90(4):518-526

Page DH, El-Hosseiny F (1983) The mechanical properties of single wood pulp fibres. Part VI. Fibril angle and the shape of the stress-strain curve. J Pulp Paper Sci 9(4):TR99TR100

Pasini D (2008) On the biological shape of the Polygonaceae rheum petiole. Int J Des Nat Ecodyn 3(1):1-26

Revol J-F, Dietrich A, Goring DAI (1987) Effect of mercerization on the crystallite size and crystallinity index in cellulose from different sources. Can J Chem 65:1724-1725

Revol J-F, Bradford H, Giasson J, Marchessault RH, Gray DG (1992) Helicoidal self-ordering of cellulose microfibrils in aqueous suspension. Int J Biol Macromol 14:170-172

Sullivan J, Douek M (1994) Determination of carbohydrates in wood, pulp and process liquor samples by high-performance anion-exchange chromatography with pulsed amperometric detection. J Chromatogr A 671:339-350

Ulkem N, Gray DG (2006) Isolation of cellulose structures in the petiole of Apium graveolens L. In: Salmen L (eds) Proceedings of 5 th plant biomechanics conference, STFIPackforsk AB, Stockholm, pp 211-214

Werbowyj RS, Gray DG (1976) Liquid crystalline structure in aqueous hydroxypropyl cellulose solutions. Mol Cryst Liq Cryst Lett 34:97-103

Zimmermann MH (1983) Xylem structure and the ascent of sap, Chap. 3. Springer, New York 